\title{
Commentary: The train has left, but Elvis is still in the station
}

\author{
Kevin L. Greason, MD
}

\author{
From the Department of Cardiovascular Surgery, Mayo Clinic, Rochester, Minn \\ Disclosures: Author has nothing to disclose with regard to commercial support. \\ Received for publication Jan 23, 2019; accepted for publication Jan 23, 2019; available ahead of print Feb 26, \\ 2019. \\ Address for reprints: Kevin L. Greason, MD, Department of Cardiovascular Surgery, Mayo Clinic, Joseph 5-200, \\ 200 First St SW, Rochester, MN 55902 (E-mail: greason.kevin@mayo.edu). \\ J Thorac Cardiovasc Surg 2019;157:2379-80 \\ $0022-5223 / \$ 36.00$ \\ Copyright (C) 2019 by The American Association for Thoracic Surgery \\ https://doi.org/10.1016/j.jtcvs.2019.01.088
}

\section{A good decision is based on knowledge and not on numbers.}

$$
\text { -Plato, Laches }
$$

Readers of the Journal will find interest in the treatise in this issue by Nguyen and colleagues ${ }^{1}$ on the need to revamp cardiac surgical training to address the disruptive advancement of catheter-based technologies in structural heart disease. The passion of Nguyen and colleagues ${ }^{1}$ is evident in their use of phases such as "burning platform" and "call to action," along with the admonition that failure to address inadequacies of surgical training "will exclude surgeon involvement in the future." I compliment Nguyen and colleagues $^{1}$ on bringing this discussion to the Journal, but I also raise the concern that the authors have significant conflict of interests.

Nguyen and colleagues ${ }^{1}$ ask to what extent any individual adult cardiac surgeon should be proficient in catheter-based therapies. In an unspoken renouncement of the heart team, they state surgeons are uniquely positioned to offer the full spectrum of therapy in structural heart disease. This is an inward-looking view that ignores the catheter-based training and expertise of the interventional cardiology team, which in most cases is 5 years-an extensive experience that must be weighed against the 6 to 12 months recommended for surgeons in the proposed training paradigm.

The American Association for Thoracic Surgery is quite clear about the importance of the heart team. ${ }^{2}$ The 2018 Consensus document (of which J. E. Bavaria was lead author) states, "One of the cornerstones of the success of transcatheter valve programs is partnering between cardiologists and cardiac surgeons, the underlying principle being that no one individual, group, or specialty possesses all the necessary skills for optimal patient outcomes. The success of these programs depends on a group of professionals, each with their own skillset, working together to provide the best possible patient-centered care." 2 The heart team is a good thing, and it must persist.

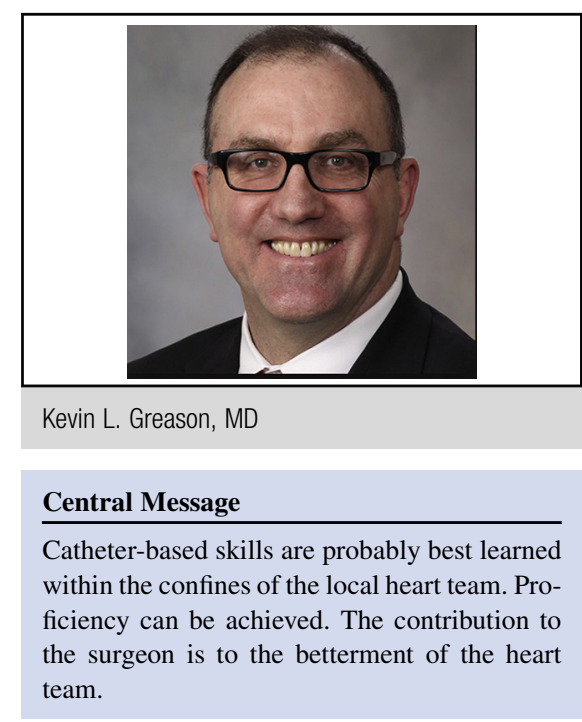

See Article page 2369.
I also believe that surgeons need better training in catheter-based therapies to add value to the Heart Team. Nguyen and colleagues ${ }^{1}$ state that lack of a standardized curriculum and training programs is a major factor keeping surgeons from obtaining the necessary catheter-based skill set (see their Table 1). I submit that their statement ignores the programs listed in Table 2 of their article. ${ }^{1}$ The lack of standardization is not limited to catheterbased therapies, however, as the only really standardized aspect of cardiac surgery training in general is the required case numbers put forth by the American Board of Thoracic Surgery.

Surgeon-specific training in catheter-based skills is a smart ideal. The question is how to achieve that end. Is the answer to be found with legislated minimal case number requirements or training paradigms? Exposure is not expertise. Not all surgeons need catheter-based skills, just as not all surgeons need ventricular assist device skills. I have participated in the advance case planning and the procedural and postprocedural management of 900 of my institution's 1500 transcatheter aortic valve insertions. I have found that the overarching rule to success is deliberate practice within the confines of the heart team. ${ }^{3}$ That is best done at the local level. And, unfortunately, it probably can't be legislated. 


\section{References}

1. Nguyen TC, Tang GH, Nguyen S, Forcillo J, George I, Kaneko T, et al. The train has left: can surgeons still get a ticket to treat structural heart disease? J Thorac Cardiovasc Surg. 2019;157:2369-76.e2.

2. Bavaria JE, Tommaso CL, Brindis RG, Carroll JD, Deeb GM, Feldman TE, et al 2018 AATS/ACC/SCAI/STS expert consensus systems of care document: operator and institutional recommendations and requirements for transcatheter aortic valve replacement: a joint report of the American Association for Thoracic Surgery, American College of Cardiology, Society for Cardiovascular Angiography and Interventions, and Society of Thoracic Surgeons. J Am Col Cardiol. 2019; 73:340-74.

3. Dearani JA, Gold M, Leibovich BC, Ericsson KA, Khabbas KR, Foley TA, et al The role of imaging, deliberate practice, structure, and improvisation in approaching surgical perfection. J Thorac Cardiovasc Surg. 2017;154:1329-36. 